\title{
O Plano de Educação Higiênica de Belisário Penna. 1900-1930
}

\author{
Ricardo Augusto Dos Santos (*) \\ (*) Casa de Oswaldo Cruz/Fundação Oswaldo Cruz. Rio de Janeiro. Brasil \\ ricardo.augusto@pq.cnpq.br
}

Dynamis

[0211-9536] 2012; $32(1): 45-68$
Fecha de recepción: 18 de julio de 2011

Fecha de aceptación: 14 de noviembre de 2011

SUMÁRIO: 1.-Introdução. 2.-Belisário Penna. 3.-Um país de homens doentes. 4.-Considerações finais.

RESUMO: Este texto tem como objetivo apresentar e analisar o projeto de educação higiênica de Belisário Penna (1868-1939). Este médico participou do Movimento Sanitarista que pretendia, através de reformas nas políticas de saúde pública e educação, modificar as condições que tornavam o Brasil um país de pobres, doentes e analfabetos. Descrevemos as principais idéias formuladas por Penna no período entre 1900 e 1930. Para tanto, utilizamos como fonte privilegiada o Fundo Pessoal do sanitarista, um dos principais intelectuais da época.

PALAVRAS-CHAVE: Eugenia, educação, movimento sanitarista, higiene, intelectuais.

KEY WORDS: Eugenics, education, sanitarian movement, hygiene, intellectuals.

\section{Introdução}

Pesquisas sobre a eugenia permanecem restritas a determinados países. Freqüentemente, ela é associada ao nazismo, ignorando-se a existência das idéias e práticas eugenistas que ultrapassaram fronteiras. O exemplo norte-americano está sendo mais estudado, assim como o eugenismo na América Latina vem merecendo mais atenção. Contudo, permanece uma produção que trata de maneira superficial as influências que o eugenismo brasileiro provocou. No Brasil, foram realizados bons trabalhos acadêmicos sobre a eugenia. Essa literatura aborda os textos dos intelectuais eugenistas, porém não demonstra a particularidade dos agentes sociais. Com alguma freqüência, analisam os livros, mas não ampliam a análise e, tampouco, 
destacam as nuances do pensamento dos intelectuais que compartilharam das idéias eugenistas ${ }^{1}$.

Cumpre indagar: o pensamento eugênico brasileiro foi diferente do anglo-saxão? O desenvolvimento da Eugenia no Brasil teve características distintas de países como EUA e Alemanha. Todavia, alguns críticos concluem, equivocadamente, que a eugenia germânica ou norte-americana foi a verdadeira, enquanto a latina foi branda ou falsa. Portanto, não cabe negar a validade das investigações realizadas, mas é necessário fazer algumas perguntas: a eugenia latina foi menos eugenista do que as outras? Foi um conjunto equivocado de idéias? Remando contra essas interpretações, constatamos que, no Brasil, entre o início do século e a década de 1940 existiu um movimento eugênico que permitia a associação entre esterilização, saneamento e educação. Quase todos os intelectuais eugenistas não escaparam dessa hibridização de estratégias.

O presente texto tem como título O Plano de Educação Higiênica de Belisário Penna. 1900-1930. Portanto, resta evidente que este médico é a figura central para a análise. Mas, não o deixaremos sozinho. Um intelectual relaciona-se com outros atores. Penna foi um dos principais agentes do campo eugênico brasileiro. Desde as primeiras décadas do século XX até a sua morte ele esteve envolvido com o debate sobre a pertinência da eugenia para a sociedade. Participou da fundação de associações que promoviam a divulgação das idéias sobre a regeneração do país. Mas, muitos

1. Para saber mais sobre o assunto, podemos mencionar algumas investigações. Em relação aos EUA, consultar Black, Edwin. A guerra contra os Fracos. A eugenia e a campanha norteamericana para criar uma raça superior. São Paulo: Girafa; 2003. Ver também o trabalho de Stern, Alexandra Minna. Eugenic nation: Faults and frontier of better breeding in modern America. Berkeley: University of California Press; 2005. Sobre a América Latina, consultar Palma, Héctor, Gobernar es seleccionar. Buenos Aires: Jorge Baudino; 2002. Ver também Miranda, Marisa; Vallejo, Gustavo, eds. Darwinismo social y eugenesia en el mundo latino. Buenos Aires: Siglo XXI; 2005. Para uma abordagem mais geral, sugiro o livro de Nancy Stepan, a primeira pesquisadora a oferecer uma interpretação sobre a Eugenia na América Latina e que não ignorou a especificidade da Eugenia Latina. Ver Stepan, Nancy. A Hora da Eugenia: Raça, Gênero e Nação na América Latina. Rio de Janeiro: Fiocruz; 2005. Consultar também Álvarez Peláez, Raquel; García González, Armando. En busca de la raza perfecta. Eugenesia e higiene en Cuba (1898-1958). Madrid: CSIC; 1999. Também indico Álvarez Peláez, Raquel; García González, Armando. Las trampas del poder. Sanidad, eugenesia y migracion. Cuba y Estados Unidos (1900-1940). Madrid: CSIC; 2007. Para o caso brasileiro, ver Dos Santos, Ricardo Augusto. Estado e eugenismo no Brasil. In: Mendonça, Sonia Regina de. Estado e historiografia no Brasil. Niterói: EdUff; 2006, p. 311-322. Consultar também Dávila, Jerry. Diploma de brancura. Política social e racial no Brasil.1917-1945. São Paulo: UNESP; 2006. 
intelectuais acompanhavam-no. O movimento eugenista foi exuberante em intelectuais, instituições e publicações ${ }^{2}$.

Como dissemos, não discordamos totalmente das interpretações realizadas por pesquisadores sobre a eugenia brasileira. Chamamos atenção, inclusive, para o bom nível dos projetos. Mas, propomos alguns questionamentos e fazemos considerações. Em primeiro lugar, afirmamos que a formação do campo eugênico relaciona-se com a estrutura de classes de cada país. A Eugenia chegou ao Brasil por intermédio dos livros produzidos na Europa. Em terras tropicais, encontrou solo fértil. Casou-se bem com um conjunto variado de idéias. Algumas delas existiam, pelo menos desde a metade do século XIX e tentavam explicar a experiência histórica em torno das populações escravas. Outras, espetacularmente desenvolvidas após 1870, almejavam construir um mundo moderno, colocando o país nos trilhos do progresso. Certamente, um dos motivos importantes para o desenvolvimento do eugenismo nas primeiras décadas do século XX estava na preocupação com o controle da população de ex-escravos que estavam em processo de proletarização.

É bastante evidente a inquietação dos intelectuais com os fatores identificados pelo eugenismo nacional como disgênicos, ou seja, contrários à formação do povo bonito, forte e saudável. Que condições adversas eram essas que impediam a formação de um Brasil novo? Entre várias, o crescimento desordenado das cidades; a proclamação da República, que também não havia resolvido os problemas que os intelectuais apontavam como cruciais; a abolição da escravidão e conseqüente processo imigratório para as cidades, compondo um contingente de pessoas procurando moradia e trabalho em cidades como Rio de Janeiro e São Paulo ${ }^{3}$.

Esse é um ponto importante para compreendermos esse emaranhado de idéias: a ambigüidade das propostas eugenistas. Rótulos à parte, o cenário é complexo. Freqüentemente, vários representantes do pensamento

2. Sobre intelectuais, instituições e publicações eugenistas do campo intelectual brasileiro, consultar Dos Santos, Ricardo Augusto. Pau que nasce torto, nunca se endireita! E quem é bom, já nasce feito? Esterilização, saneamento e educação: Uma leitura do eugenismo em Renato Kehl (1917-1937). Niterói: Tese de Doutorado em História Social/Universidade Federal Fluminense; 2008. Ver também Koifman, Fábio. Porteiros do Brasil: O serviço de visto do Ministério da Justiça e Negócios Interiores (1941-1945). Rio de Janeiro: Tese de Doutorado em História Social - IFCS/UFRJ; 2007.

3. Sobre os projetos políticos dos eugenistas e sanitaristas, consultar Boarini, Maria Lucia. Higiene e raça como projetos. Higienismo e eugenismo no Brasil. Maringá: UEM; 2003. 
eugenista são ignorados como exemplos para estudar a repercussão dessas idéias. Há duas razões. Em primeiro lugar, os pesquisadores contemporâneos trabalham com os conceitos formulados pelos intelectuais estudados. Em segundo, o paradigma eugênico anglo-saxão influencia as análises operadas pela historiografia da eugenia. Por meio de uma leitura tradicional, qualquer proposta fora do modelo paradigmático não será considerada eugênica. Daí a identificação direta entre nazismo e eugenia, o que constitui flagrante equívoco. Como explicar as experiências eugenistas acontecidas na Suécia, que até meados do século XX praticou a esterilização compulsória? Ou nos EUA, que em 1906 já realizava a esterilização compulsória e consagrava a eugenia nas suas políticas públicas?

Julgamos que nossa contribuição ao debate historiográfico sobre a Eugenia Brasileira está em demonstrar a articulação da educação higiênica, das ações de esterilização e do combate às doenças para a formação de um povo educado e higiênico. Mesmo Renato Kehl (1889-1974), médico reconhecido como um eugenista radical, favorável às técnicas de esterilização de incapazes mentais e criminosos, foi também defensor do saneamento e da educação higiênica como fatores que propiciariam a regeneração dos brasileiros, identificados como pobres, doentes e feios. Na década de 1920, Kehl já declarava a importância e o valor dos ensinamentos da educação higiênica. Ao longo do texto, ainda que de maneira superficial, exploraremos a ação intervencionista da educação no projeto eugênico brasileiro. Isto nos ajuda a entender mais sobre a especificidade da eugenia. Quase todos os intelectuais eugenistas possuíam uma visão particular das funções que a educação higiênica desempenharia na construção do povo ${ }^{4}$.

A investigação das idéias eugenistas na trajetória dos intelectuais deve ser apurada com critério rigoroso. A concepção de educação preconizada por Penna apresentava-se integrada à transformação da sociedade. Assim, podemos resumir que os intelectuais mantinham propostas de intervenção eugênica do seguinte tipo: para as classes cacogênicas e disgênicas da sociedade, ações eugenistas, defendendo a esterilização para conter a proliferação dos seres degenerados, mestiços e doentes; para todos que pretendiam

4. Renato Kehl foi um dos principais nomes da Eugenia da América Latina. Dentre sua volumosa obra indicamos para consulta os livros mais importantes. Kehl, Renato. Aparas eugênicas. Sexo e civilização. Novas diretrizes. Rio de Janeiro: Francisco Alves; 1933. Kehl, Renato. A Cura da Fealdade. Eugenia e medicina social. São Paulo: Monteiro Lobato; 1923. Kehl, Renato. Lições de eugenia. Rio de Janeiro: Francisco Alves; 1929. 
casar-se, o exame pré-nupcial, terminando na proibição do casamento ou geração de filhos entre os que demonstrassem ser degenerados ou perigosos para a sociedade; e, para os membros da classe aristogênica, educação higiênica e sexual para garantir uma descendência sadia ${ }^{5}$.

Podemos definir que os planos de eugenistas e sanitaristas consistiam em eugenia preventiva (controle dos fatores disgênicos pelo saneamento), em eugenia positiva (educação, incentivo e regulação da procriação dos capazes) e na eugenia negativa (evitar a procriação dos incapazes). O objetivo era modernizar o país e apagar os símbolos da degeneração. Dos sanitaristas, que negavam as teses da inata indolência tropical, vieram os remédios para um futuro promissor: a educação higiênica e as ações públicas sanitárias. As condições sanitárias teriam de modificar-se para que, transformando os indivíduos, os seus descendentes fossem beneficiados. Eugenistas e sanitaristas entendiam que as reformas das políticas públicas de saúde aprimorariam a capacidade hereditária. Em suma, coexistiam teorias que adotavam uma seleção racial capaz de embranquecer a população, produzindo um tipo nacional, com teses de que o futuro eugênico seria resultado do saneamento das áreas rurais e urbanas, além da educação higiênica que propiciaria a criação e manutenção da nova ordem. Essa amplitude de técnicas eugênicas não consistia em interpretação errônea de teorias científicas originais, nem mesmo uma cópia importada sem critério, mas sim na construção de um pensamento eugênico brasileiro ${ }^{6}$.

Eugenistas e sanitaristas, como tantos grupos do campo intelectual da época, não formavam conjuntos homogêneos. Por exemplo, uma parcela de eugenistas negava a influência do meio. Ou, pelo menos, alinhava-se em torno de uma leitura que afirmava a impossibilidade de transmissão hereditária de características adquiridas. Podemos dividir os intelectuais em dois conjuntos. Um grupo aceitava a transformação das gerações fu-

5. A aristogenia representava os seres eugenicamente superiores. Os tipos inferiores constituíam a classe cacogênica. Esses poderiam assumir uma forma bastante degradada, ou seja, a disgênica.

6. Embora discordando das suas interpretações sobre a Eugenia no Brasil, indico esta dissertação para melhor conhecimento do tema. Para esse autor, houve cortes e até uma evolução na trajetória da Eugenia. Diferentemente, em meu trabalho, considero que as diferenças entre as propostas e autores eugenistas e sanitaristas representavam tensões e conflitos inerentes ao campo intelectual. Souza, Vanderlei Sebastião de. A política biológica como projeto: A eugenia negativa e a construção da nacionalidade na trajetória de Renato Kehl (1917-1932). Rio de Janeiro: Casa de Oswaldo Cruz; 2006. 
turas por meio da alteração do meio, via combate dos fatores disgênicos, isto é, degenerativos, como as doenças venéreas e o alcoolismo; e o outro negava, ou argumentava que essas causas ocupavam um espaço secundário. No entanto, tal divisão, se em algum momento ficava evidente, em outros, no seio da disputa por espaços políticos e culturais, transformava-se numa fronteira bastante maleável.

\section{Belisário Penna}

«Impõe-se, portanto a primazia da educação higiênica e eugênica na escola e no lar, como medida fundamental para a formação de uma mentalidade coletiva equilibrada, e de uma consciência sanitária, isto é, de um espírito nacional absolutamente compenetrado do valor inestimável da prática dos preceitos da higiene e da eugenia, como indispensáveis à prosperidade individual, da família, da sociedade e da espécie» ${ }^{7}$.

O discurso apresentado pelos intelectuais sobre as condições de saúde pública apresentava-se articulado à determinado conjunto de conhecimentos e práticas sociais políticas. Seu objetivo era obter dos indivíduos uma conduta correta, segundo as regras ditadas pelas disciplinas que estavam transformando o mundo. As descobertas no campo da microbiologia desvendaram os processos infecciosos provocados por organismos que causavam doenças como Cólera, Varíola e Febre Amarela. No entanto, as estratégias adotadas para a melhoria das condições médico-sanitárias exigiram que o campo de ação ultrapassasse a transmissão dos conhecimentos científicos, provocando sensíveis modificações sobre os modos de vida das populações atingidas. As normas de educação preconizadas pretendiam controlar os hábitos dos indivíduos, prevendo-se que a alteração dos comportamentos evitaria o contágio das doenças ${ }^{8}$.

7. Penna, Belisário. Educação higiênica e eugênica-Impõe-se a Primazia da Educação Hygienica Escolar. 1927. Departamento de Arquivo e Documentação/Casa de Oswaldo Cruz. Rio de Janeiro. Fundo Pessoal Belisário Penna. Datilografado. BP/PI/TP/19271226, p. 2.

8. Antes de o paradigma bacteriológico tornar-se dominante, as explicações mais comuns para as doenças infecto-contagiosas eram os miasmas ou os castigos divinos. Sobre o assunto, consultar Rosen, George. Uma história da saúde pública. São Paulo: Hucitec; 1994. Sobre este tema no Brasil, ver Hochman, Gilberto. A era do saneamento: as bases da política de saúde pública no Brasil. São Paulo: Hucitec/Anpocs; 1998. 
Todavia, as ações médicas invadiram o âmbito da vida privada. Evidentemente, as mudanças realizadas melhoraram as condições sanitárias das cidades. Porém, não devemos ignorar que as regras higiênicas confundiram-se com as normas sociais relacionadas ao controle das classes com o intuito de evitar os conflitos sociais, como podemos averiguar lendo os textos do sanitarista Belisário Penna. Em inúmeros artigos e panfletos, este médico manifestou o desejo de modificar o país a partir de uma consciência sanitária:

«Somente com essa educação, as medidas sanitárias compendiadas em leis e regulamentos terão o indispensável assentimento voluntário e convencido do povo» ${ }^{9}$.

Mas, quem foi Belisário Penna? Trata-se de um dos intelectuais mais importantes para estudarmos o período. Belisário Penna é personagem central para a história da saúde pública, mas sua biografia ainda é desconhecida. É bastante comum encontrarmos dados equivocados sobre a vida do sanitarista. Achamos, com frequência, em livros e artigos, a seguinte frase: Belisário Penna, cientista do IOC. Penna não era cientista e tampouco foi membro do Instituto Oswaldo Cruz.

Belisário Augusto de Oliveira Penna nasceu em Barbacena (MG), em 29 de novembro de 1868, filho do Barão de Carandaí e de Lina Lage Penna. Ingressou, em 1886, na Faculdade de Medicina do Rio de Janeiro, transferindo-se no último ano para Salvador, na Bahia, onde terminou o curso em novembro de 1890. Retornando à Minas Gerais, clinicou em Barbacena e Juiz de Fora. Nessa última, em 1903, foi eleito vereador. No ano seguinte, transferiu-se para o Rio de Janeiro e prestou concurso para inspetor sanitário da Diretoria Geral de Saúde Pública, órgão responsável pelas políticas de saúde pública. Aprovado, foi designado para exercer as suas funções numa área da cidade habitada por imigrantes portugueses, italianos, judeus e negros. Quase todos pobres. Nesse momento, começou o envolvimento de Penna com as políticas de saúde ${ }^{10}$.

9. Penna, Belisário. Saúde, Trabalho e Educação. 1920. Departamento de Arquivo e Documentação/ Casa de Oswaldo Cruz. Rio de Janeiro. Fundo Pessoal Belisário Penna. Datilografado. 3 folhas. BP/PI/TP/19202040-1, p. 3.

10. Sobre Penna, consultar Thielen, Eduardo Vilela; Dos Santos, Ricardo Augusto. Belisário Penna: notas fotobiográficas. Manguinhos. História, Ciências e Saúde. 2002; 9 (2): 387-404. 
Mas, sua trajetória não ficou restringida a capital da República brasileira. Alguns anos depois, designado pelo médico Oswaldo Cruz, juntamente com o cientista Arthur Neiva do Instituto Oswaldo Cruz, percorreu grande parte do Brasil. Conheceu o norte da Bahia, sudeste de Pernambuco, sul do Piauí e nordeste de Goiás, com o fim de estudar as condições sanitárias destes estados. As experiências dessa viagem foram decisivas para a sua visão do país. As condições miseráveis da população marcaram-no fortemente. Transformou-se num incansável pregador da educação higiênica como caminho necessário para a superação dos problemas sociais da doença e miséria que tanto afligiam o Brasil ${ }^{11}$.

Em 1913, Belisário Penna solicitou uma licença de seis meses e, por conta própria, percorreu os estados do Paraná, Santa Catarina e Rio Grande do Sul, para estudá-los, como fizera em relação aos do Norte. Retornando ao Rio de Janeiro, reassumiu o cargo de Inspetor Sanitário, passando a trabalhar em bairros distantes do centro da cidade. Em Vigário Geral, instalou, em março de 1916, o primeiro posto de profilaxia rural do Brasil, que mais tarde seria transferido para as localidades de Parada de Lucas e Penha. Em 1916, iniciou pelo jornal O Correio da Manhã, uma campanha pelo Saneamento do Brasil, escrevendo os artigos que constituiriam o livro publicado com este nome. Em maio de 1918, durante a presidência de Wenceslau Brás, Penna seria nomeado para o recém-criado Serviço de Profilaxia Rural. Durante a sua direção, dez postos sanitários foram instalados nos subúrbios e zonas rurais do Distrito Federal. Na mesma época, ele seria o principal dirigente de importante associação reunindo políticos, escritores e médicos, a Liga Pró-Saneamento do Brasil. Esse grupo reivindicava reformas nas políticas de saúde.

Em virtude da autonomia administrativa obtida junto ao Ministério da Justiça e Negócios Interiores, os recursos financeiros do Serviço de Profilaxia Rural foram aumentados e a assistência médica foi ampliada para as áreas do Estado do Rio de Janeiro limítrofes com o Distrito Federal. Em 1920, com a criação do Departamento Nacional de Saúde Pública (DNSP), uma

11. As origens do Instituto Oswaldo Cruz remontam a fundação do Instituto Soroterápico Federal, cujo objetivo inicial foi a fabricação de soros e vacinas contra a peste bubônica. Em 1907, passou a denominar-se Instituto de Patologia Experimental de Manguinhos, mas em homenagem a Oswaldo Cruz, recebeu o nome de Instituto Oswaldo Cruz. Sobre o IOC, consultar Benchimol, Jaime. Manguinhos do sonho à vida: a ciência na Belle Epoque. Rio de Janeiro: Casa de Oswaldo Cruz; 1990. 
antiga demanda dos intelectuais sanitaristas, um órgão nacional que fosse responsável pelas ações para a área da saúde, Penna foi nomeado Diretor do Departamento de Saneamento e Profilaxia Rural, um setor subordinado ao DNSP. Foram instalados serviços de profilaxia em 15 estados durante a sua gestão. Penna também teve uma forte atuação política. Em carta aberta aos filhos, publicada nos jornais, apoiou a Revolta Tenentista de 5 de julho de 1924. Preso, ficou detido por seis meses ${ }^{12}$.

Em 1927, ainda suspenso de suas funções, foi reintegrado ao serviço público como Chefe do Serviço de Propaganda e Educação Sanitária. Neste cargo, percorreu os estados de Minas Gerais, Alagoas, Pernambuco, Paraíba e Rio Grande do Norte até ser requisitado em 1928 pelo governo do Rio Grande do Sul para organizar um centro de educação sanitária. Transferindose para o Sul, iniciou um período de intenso trabalho. Merece destaque seu engajamento na Revolução de 1930. Após a vitória do movimento, foi nomeado Diretor do Departamento Nacional de Saúde. Em setembro de 1931, Penna assumiu interinamente o Ministério da Educação e Saúde, criado depois do levante que levou Getúlio Vargas ao poder. Filiou-se, em 1932, à Ação Integralista Brasileira (AIB), fundada por Plínio Salgado, tornando-se membro da Câmara dos 40. Belisário Penna faleceu em 4 de novembro de $1939^{13}$.

Os registros documentais assinalam que Belisário Penna, a partir de 1904, quando se envolveu com as intervenções governamentais nas ações sanitárias públicas, teve um papel decisivo para marcar a importância dessas atividades, desde a sua emergência como responsabilidade estatal. Daquele ano até a década de 1930, Penna esteve sempre ligado à direção dos órgãos governamentais, intervindo na sociedade com a criação de entidades políticas. Participou da construção não só de um setor público voltado para controlar as ações coletivas da saúde, mas também na formação de um grupo técnico com práticas próprias, ou seja, os educadores e sanitaristas, que deram capacidade intelectual e executiva aos projetos.

12. Tenentismo foi um movimento político de jovens oficiais de baixa patente do exército brasileiro. Descontentes com a República proclamada em 1889, esses militares propunham reformas na estrutura de poder do país.

13. Câmara dos 40 era um órgão consultivo constituído por intelectuais dirigentes da Ação Integralista Brasileira (AIB). O Integralismo foi um movimento político que teve grande vigor no Brasil nos anos 1930. Contrário ao liberalismo político e as ideias socialistas, conquistou grande parte das classes médias, tendo entre seus 500.000 filiados, vários profissionais médicos e advogados. 
Os documentos que compõem seu arquivo pessoal estão sob a custódia do Departamento de Arquivo e Documentação da Casa de Oswaldo Cruz. São 7.000 documentos produzidos e acumulados pelo sanitarista, entre relatórios, cartas e fotos, que revelam aspectos inéditos sobre a história do Brasil. Esse intelectual foi colaborador incessante da imprensa, autor de livros e membro da administração pública de vários órgãos. Entre os documentos de seu arquivo encontramos textos que fornecem dados imprescindíveis para uma investigação sobre o caráter das ações em saúde. Dentre essas fontes, apresentaremos comentários a respeito de alguns documentos.

Um texto de 1905 é essencial para a nossa análise. Trata-se do relatório apresentado ao dirigente da Diretoria Geral de Saúde Pública, o médico Oswaldo Cruz. Veremos que a leitura desse documento permite identificar a existência de práticas educativas e/ou coercitivas que os inspetores utilizavam para obter os objetivos. Penna afirmava que nenhum regulamento sanitário teria execução eficiente se não fosse precedido de inteligente propaganda para esclarecer o povo sobre as vantagens ${ }^{14}$.

Nesse relato dos trabalhos efetuados durante o ano de 1904, pelo inspetor sanitário Belisário Penna, achamos preciosos exemplos a respeito do modo persuasivo que Penna utilizava para cumprir as rigorosas regulamentações do código sanitário da época. Documento do maior interesse, pois traz a descrição das tarefas de um inspetor de higiene no mesmo momento e em torno das mesmas questões que transformaram a cidade num caos. O documento fala de sua bem sucedida atuação em zona próxima às ruas tumultuadas pelo movimento popular que provocou transtornos na capital da República: A Revolta da Vacina. Um dos movimentos populares mais estudados pela historiografia brasileira. Acontecida entre 10 e 16 de novembro de 1904, a Revolta foi um movimento de oposição à vacinação contra a varíola. Os revoltosos resistiam à violência dos agentes sanitários e ao rigor das normas sanitárias, mas também questionavam o método empregado. Articulações políticas, tanto por parte de frações monarquistas quanto de republicanos insatisfeitos com a Proclamação da República em 1889, colaboraram para a eclosão do acontecimento.O pretexto para o conflito foi a publicação do decreto de obrigatoriedade da vacina, o que gerou um movimento popular contra a lei que tornava a vacinação antivariólica compulsória. No entanto,

14. Penna, Belisário. Relatório anual do inspetor sanitário Doutor Belisário Penna. 1905. Departamento de Arquivo e Documentação/Casa de Oswaldo Cruz. Rio de Janeiro. Fundo Pessoal Belisário Penna. Datilografado. 23 folhas. BP/PI/TP/19050118. 
apesar do período do relatório ter coincidido com o estado de sítio instalado pelo governo da União diante das manifestações populares, não há nenhum comentário específico de Penna a respeito dos fatos. Embora sejam feitas observações sobre as condições de vida da população e sobre o projeto de obrigatoriedade da vacina ${ }^{15}$.

Nomeado inspetor sanitário a 05 de maio de 1904, Penna iniciara sua atividade numa área que compreendia as ruas Marquês de Sapucaí, Santana, General Pedra, Senador Eusébio, Visconde de Itaúna, São Leopoldo, Alcântara e Marquês de Pombal, zona de pequeno comércio e inúmeros cortiços. O relatório foi apresentado em 08 de janeiro de 1905 e narra os serviços realizados entre 17 de maio e 31 de dezembro de 1904. Dedicando-se à vigilância médica e à vacinação, Penna encontrou relutância da população, mas logo essa resistência foi vencida ${ }^{16}$. Como foram superados os obstáculos para convencer os habitantes a seguir as regras? Os bons resultados devem ser creditados às ameaças que Penna fazia. Como por exemplo, a de recolher os habitantes aos hospitais, conseguindo assim vaciná-los. Devido ao medo de entrar nos recintos de um local associado à morte, parece que os habitantes daquele pedaço da cidade concordavam com a vacinação. Além da coerção explícita aos comerciantes proprietários de pequenos açougues e mercearias, havia o convencimento através de ameaças e preleção pedagógica do inspetor. Demonstrando as vantagens de uma vida sadia, Penna ameaçava com multas aos que não cumprissem a necessária profilaxia higiênica dos prédios e produtos colocados à venda:

«Tática e habilidade para educar e convencer esse povo obliterado de abusões e princípios falsos, alheio inteiramente aos mais comezinhos preceitos de higiene, que, parece-me não tinha sido até então aplicado com seriedade e com ânimo firme de ver realizado e cumprido os seus regulamentos» ${ }^{17}$.

Portanto, o trabalho do inspetor era de vacinação, vigilância médica e polícia médica, inclusive, multando os comerciantes, donos de armazéns e estalagens imundas, repletas de doenças e animais, que se negavam a

15. Sobre o assunto, consultar Sevcenko, Nicolau. A Revolta da Vacina: mentes insanas em corpos rebeldes. São Paulo: Scipione; 1993. Ver também Carvalho, Jose Murilo de. Bestializados: o Rio de Janeiro e a República que não foi. São Paulo: Companhia das Letras; 1991.

16. Cortiço é uma habitação coletiva de pequenas casas ou quartos para a população pobre.

17. Penna, n. 14, p. 8 . 
cumprir as recomendações sanitárias. Belisário Penna descreve a função educativa e coercitiva dos inspetores:

«O inspetor é quem está em contato direto e imediato com a população; quem executa o regulamento; quem aplica penas; quem atende em primeiro lugar as reclamações, cabe a maior responsabilidade na execução da lei, que é benéfica em seus efeitos, mas dura na aplicação.

O povo, em geral, tem aversão à remoção para hospitais de isolamento, e esse sentimento, aliás injustificável e filho apenas da sua ignorância absoluta em matéria de higiene, foi um elemento por mim aproveitado para conseguir vacinações (...) O povo, em geral, é obediente e submisso, aceitando os conselhos e determinações da autoridade sanitária, que vai cumprindo sem grande dificuldade o regulamento sanitário, notando eu com grande satisfação que as condições sanitárias melhoraram sensivelmente» ${ }^{18}$.

Nas primeiras décadas do século, as políticas de saúde pública pautavam-se preponderantemente por atividades campanhistas, ou seja, suas estratégias de intervenção atendiam ao controle das doenças infectocontagiosas: Varíola, Febre Amarela e Peste Bubônica. Durante o decorrer dos anos, apareceram experiências sanitárias que apontaram para outras estratégias de assistência em saúde. Assim, dá-se não só o surgimento das expedições científicas com o objetivo de estudar as condições de ocorrência das doenças, como a criação de postos sanitários permanentes, que para Penna deveriam ser escolas de ensinamentos higiênicos. Uma das linhas do nosso trabalho é demonstrar que os membros do Movimento Sanitarista, especialmente Belisário Penna, adotaram estratégias educativas e/ou coercitivas conjugadas às ações sanitárias tradicionais que se propunham a eliminar as doenças da ignorância ${ }^{19}$.

Penna esteve à frente de uma das expedições científicas que excursionaram pelas áreas mais inóspitas do país. Essas viagens patrocinadas pelo Instituto Oswaldo Cruz influenciaram as análises de vários intelectuais. Penna participou, ao lado de Arthur Neiva, da expedição que percorreu vários estados. O diagnóstico duro da realidade infernal dos sertões fez

18. Penna, n. 14, p. 7

19. Convém salientar a complexidade dos modelos de atenção à saúde das populações. Não existiu um afastamento das correntes de políticas das ações médicas. Houve um encaminhamento da polícia médica para a prevenção, em que a questão educativa foi sendo enfatizada. Sobre os serviços de saúde e seus modelos, Consultar Merhy, Emerson Elias. A Saúde Pública como Política. Um estudo de formuladores de políticas. São Paulo: Hucitec; 1992. 
com que considerasse de forma especial a sua visão. Afinal, ele conhecera a realidade nacional. O sanitarista retornaria a este ponto, criticando, com relativa freqüência, os que pensavam o Brasil a partir das luxuosas avenidas construídas à beira-mar. Formulando seu Plano de Educação Higiênica como meio de chegar às boas condições higiênicas e a integração nacional, criticava os intelectuais indiferentes ao país real.

Mas, que Plano era este? Penna chegou a formular um projeto de educação higiênica com o intuito de transformar a nação. Em vários momentos de sua vida, Penna tentaria implantar seu projeto educativosanitarista-eugênico. Vejamos outro documento do seu arquivo pessoal. No texto Educação Higiênica e Eugênica - Impõe-se a Primazia da Educação Hygienica Escolar, apresentado na $1^{\text {a }}$ Conferência Nacional de Educação da Associação Brasileira de Educação, ele propunha uma intervenção na sociedade, capaz de homogeneizar as atitudes. Para ele, a consciência sanitária só teria condições de se firmar nos países nos quais predominasse a saúde, base para o trabalho produtivo. Este não era o caso, onde a miséria e a doença eram consequências inevitáveis da ignorância. Por isto, tornava-se indispensável criar a consciência coletiva pela educação higiênica, como meio de difundir os valores morais da normalidade resultante da saúde. Até a saída da vida pública em 1933, Penna irá insistir nessas palavras. Inúmeros textos chamando atenção para a salvação do país através da educação fazem parte de seu arquivo.

Sem dúvida, por meio desta argumentação, caberia à educação higiênica gerar uma nova sociedade, adequada aos ideais de racionalidade e produtividade capitalistas. Com base nela, formularam-se normas sobre o lazer, trabalho, educação e família. Visando um Brasil moderno e pacífico, os intelectuais sanitaristas expressavam um ideário que buscava civilizar o cidadão, seus espaços e relações. Tornava-se absolutamente necessário obter controle sobre os problemas que atuavam sobre a saúde da sociedade, entre os quais se incluíam os hábitos dos indivíduos. Assim, para levar adiante o projeto higiênico, seria vital a cooperação da educação. Desse quadro emergia a convicção de que o país entraria no caminho da civilização, identificada esta com a própria educação higiênica, a partir do momento em que princípios profiláticos básicos fossem seguidos.

«A Educação Higiênica, que será a sua incorporação real à civilização, só se fará, não apenas quando ele souber ler e escrever, mas quando se convencer de que deve construir a sua habitação de acordo com os preceitos da 
higiene, quando aprender a alimentar-se, a beber água limpa, a defender-se de insetos e parasitas transmissores e causadores de doenças, quando se dispuser à prática das virtudes higiênicas do asseio e da sobriedade» ${ }^{20}$.

O Movimento Sanitarista foi um movimento político de médicos, educadores, políticos, escritores e advogados. Para os participantes, saúde e educação eram elementos cruciais para a construção da identidade nacional. Os intelectuais sanitaristas consideravam a República federativa, ou seja, com a relativa autonomia dos estados, dominados pelas oligarquias regionais, um obstáculo para a reforma das políticas públicas de saúde visando o combate às doenças. Penna defenderia o saneamento e a educação higiênica para todo o país, tendo como objetivo a integração nacional e a erradicação das doenças. Este foi o grande símbolo da reforma sanitária postulada pelo movimento sanitarista: o papel do médico não era somente cuidar de indivíduos, mas curar a própria sociedade. Observamos que, aliado à estratégia de criação dos postos sanitários permanentes, Penna elaboraria novos projetos para a intervenção governamental no campo das ações de saúde pública. Considerava que o médico deveria atuar de diversas formas, isto é, colaborando no Plano de Educação Higiênica, inserido no planejamento de saúde, porém sem abandonar as ações campanhistas de combate às epidemias.

«A propaganda, feita inteligentemente nas escolas, colégios, fábricas, quartéis e fazendas, em linguagem simples, clara e convincente, acompanhada de projeções elucidativas de fatos e coisas reais; seguida de folhetos e cartazes ilustrados; o ensino individual e familiar nos postos sanitários e nos domicílios, pelos médicos, guardas sanitários, educadores de saúde, têm capital importância e facilitam sobremaneira a tarefa dos higienistas na aplicação das medidas regulamentares, que passam a ser cumpridas pelo povo, com boa vontade, por convicção da sua utilidade, e não apenas pelo temor das penalidades legais» ${ }^{21}$.

Estas foram algumas das estratégias adotadas para o Plano de Educação Higiênica. Através delas, ultrapassavam-se os modelos exclusivamente baseados no combate aos problemas por meio da vigilância médica e

\footnotetext{
20. Penna, Belisário. Propaganda Sanitária. S. D. Departamento de Arquivo e Documentação/Casa de Oswaldo Cruz. Rio de Janeiro. Fundo Pessoal Belisário Penna. 4 folhas. BP/PI/TP/90002040-18.

21. Penna, n. 20.
} 
campanhas sanitárias. Belisário Penna superou, portanto, também os que, como ele, afirmavam que a miséria das áreas rurais era um problema. Valorizou as experiências dos serviços de saúde pública do começo do século; porém, ao associar práticas típicas da polícia sanitária, não desprezaria o serviço dos postos sanitários. Os recursos educativos e coercitivos deveriam integrar o projeto. O uso da força cedia espaço para que a educação e a higiene não se impusessem repressivamente, mas por meio de práticas de convencimento. Portanto, uma concepção nova invadiu o espaço da vigilância médica. Um deslocamento do policiamento para a educação sanitária. Na prática, a tarefa de vigiar a cidade, as habitações e os indivíduos, ganhava um poderoso aliado, a persuasão. As ações médicas no plano das relações sociais objetivavam preservar os vínculos a que pertenciam os indivíduos (família, trabalho, Estado) e assim contribuir para a reprodução da ordem social.

\section{Um país de homens doentes}

Um imenso país, de vastas terras; uma natureza exuberante, onde tesouros estavam à espera do homem. Um paraíso terrestre. Esse país fantástico não pertencia apenas ao imaginário de poetas. Assim, pensava boa parte dos intelectuais brasileiros. Mas esse paraíso tinha problemas. Além da miséria escandalosa, havia as doenças. As grandes avenidas, os cafés, os teatros luxuosos confundiam-se com os espaços ocupados pelos pobres, analfabetos e doentes. Para uma corrente do pensamento social, a construção da nação estaria radicada na adaptação aos padrões culturais europeus, de onde se originava um discurso que condenava a miscigenação racial e os hábitos. Outra corrente defendia que a implantação da nacionalidade verde-amarela dependeria da rejeição dos modelos estrangeiros importados ${ }^{22}$.

Quando Penna e Arthur Neiva embarcaram rumo as regiões distantes das grandes cidades talvez tivessem algumas idéias sobre o que iriam encontrar. Depois, certamente, as experiências vividas deram àqueles homens os tons da realidade com que se depararam: as precárias condições do país. Mas, o que eles viram possibilitou a certeza de que para reverter a

22. Sobre a Questão racial no pensamento social Brasileiro, consultar Dos Santos, Ricardo Augusto. Lobato, os Jecas e a Questão racial no pensamento Social Brasileiro. Revista Achegas. 2003; número 7. Disponível em: www.achegas.net [citada 5 Abr 2011]. 
terrível realidade era necessário conhecer os problemas. Várias expedições percorreram o território naqueles anos. Viajar pelas imensas regiões do país representava um ato fundamental para a compreensão da identidade nacional. Era preciso ver o Brasil, conhecer as doenças, modos e condições de vida. Com essas preocupações, Penna e Neiva registraram o Brasil real no diário de viagem da expedição. A construção da identidade nacional dava-se através da visão e diagnóstico do país. Ele estava doente, improdutivo para os padrões modernos de racionalidade econômica capitalista. Urgia uma transformação. Era preciso construir a nação. O relatório de Penna e Neiva descreveu uma visão mais realista das condições sociais do país. Em 1916, o texto foi publicado, registrando a miséria, as doenças e o isolamento das populações, narrando os problemas sociais como se os expedicionários estivessem à procura de doenças num organismo social, observando sintomas e diagnosticando ${ }^{23}$.

Mas, qual o nexo deste momento com o Plano de Educação Higiênica de Penna? O projeto higienista projetava mais que regras escolares, pois pretendia controlar hábitos sociais e transformar o país. A educação higiênica orientaria a constituição de uma ordem social, a qual presidiria a higiene das escolas, lares e cidades. Esta proposta de intervenção social traduziu-se na valorização de questões morais, como a erradicação de maus hábitos, tendo como ideal um modo de vida, aonde o trabalho e a família seriam modelados. Penna apresentaria várias propostas de educação higiênica para o país com o desejo de modificá-lo. No trabalho apresentado na Conferência Nacional de Educação da ABE, encontra-se um projeto para a construção do mundo do trabalho, da escola e do lar. Segundo jornais da época, a sua leitura foi muito aplaudida, suscitando entrevistas e matérias em vários periódicos. $\mathrm{O}$ texto registra propostas de controle social através das normas sanitárias. O universo da higiene, segundo Penna, compreen-

23. Arthur Neiva nasceu em 22 de março de 1880. Em 1912, com Penna, chefiou a expedição que percorreu diferentes estados do país. Quatro anos depois, Penna e Neiva publicaram o relatório da viagem denunciando as péssimas condições de saúde. Esse estudo foi importante por apresentar considerações diferentes das caracterizações idílicas dominantes. Neiva integrou o movimento sanitarista que congregou intelectuais em prol do saneamento. Em 1916, assumiu a direção do Serviço Sanitário do Estado de São Paulo, onde promoveu uma reforma dos serviços de saúde. Neiva faleceu no Rio de Janeiro em 6 de junho de 1943. Consultar Casa de Oswaldo Cruz. A Ciência a Caminho da Roça: Imagens das Expedições Científicas do Instituto Oswaldo Cruz ao Interior do Brasil, entre 1911 e 1913. Rio de Janeiro: COC/FIOCRUZ; 1991. 
dia rigoroso controle sobre os problemas que atuavam sobre a saúde do indivíduo, entre os quais se incluíam as atitudes. Penna dava destaque a esta participação na Conferência. Em carta a Monteiro Lobato, onde realiza uma reconstituição mítica de sua trajetória profissional, ele descrevia a sua importância:

«Sigo agora, chamado pelo governo do Rio Grande do Sul, onde vou, com ampla autonomia, organizar o serviço de higiene do estado e criar a escola de propaganda e educação sanitária na escola e no lar - segundo o plano que apresentei à primeira Conferência de Educação Nacional, reunida em dezembro do ano passado» ${ }^{24}$.

Penna ressaltava a importância da educação higiênica e eugênica, começada desde a escola primária, a fim de, por esse ensino, construir a consciência sanitária nacional. A partir daí, a educação seria o melhor instrumento para alcançar a desejada adaptação do indivíduo ao meio social. Preparação do corpo pela educação física; da mente pela educação moral; do intelecto pela educação formal e para o trabalho pela educação profissional. Assim, os pressupostos da educação higiênica e eugênica seriam obedecidos. A educação atingiria os costumes, tendo por objetivo formar indivíduos produtivos e saudáveis. Várias técnicas surgiram visando enquadrar as atitudes infantis, planejando educar higienicamente para toda a existência.

«Para isso torna-se indispensável criar a consciência sanitária, pela educação higiênica na escola, no lar, nas fábricas e nas casernas, a fim de gravar no espírito de toda a gente o valor inestimável - econômico, étnico, moral e social - da normalidade biológica resultante da saúde, conquistada pela obediência às leis inflexíveis da biologia, com a execução de medidas de saneamento; pela prática das virtudes higiênicas do asseio, da sobriedade, da castidade» ${ }^{25}$.

24. Penna, Belisário. Correspondência com Monteiro Lobato. 1928. Departamento de Arquivo e Documentação/Casa de Oswaldo Cruz. Rio de Janeiro. Fundo Pessoal Belisário Penna. BP/ COR/19151126. Sobre Associação Brasileira de Educação, Consultar Carvalho, Marta Maria Chagas. Molde nacional e forma cívica: Higiene, moral e trabalho no projeto da Associação Brasileira de Educação. 1924-1931. Bragança Paulista: EDUSF; 1998.

25. Penna, n. 7, p. 3. 
Para solucionar os problemas relativos à saúde pública seria necessário, portanto, educar a população com conhecimentos higiênicos e eugênicos para que adquirissem modos de vida sadios. Contribuindo para reforçar as atividades de educação higiênica destinadas à formação de hábitos, a criança, a mãe e a professora seriam alvos das políticas públicas. A criança passou a ser um indivíduo capaz de absorver conhecimentos, portanto, um cidadão que poderia ser moldado de acordo com as normas propostas. A preocupação em educar a criança levou, por extensão, à família, particularmente à mãe, ressaltando-se a importância do ensino da puericultura às moças que seriam as futuras genitoras, como também o preparo educativo daquelas que eram mães.Além do surgimento dos especialistas em cuidar da vida das gestantes e crianças, pediatras, ginecologistas e obstetras, era crescente o mercado de laticínios e produtos farmacêuticos dirigidos às mães e crianças ${ }^{26}$.

«A mulher encontrará a verdadeira esfera de ação, adequada ao sexo e aos seus deveres, no desempenho das funções do lar, da família, da escola e de tudo quanto tenha relação com esses fundamentos das sociedades moralizadas e sadias» ${ }^{27}$.

Evidentemente, a tentativa de controle social total sonhada pelos intelectuais eugenistas e sanitaristas foi completa de falhas. Todavia, foi suficientemente eficaz. Neste ponto, devemos alertar e deixar claro que estamos analisando as idéias contidas nos discursos de Penna. O projeto médico dos intelectuais para controlar seus habitantes não foi totalmente efetivado. Entretanto, não foi um sonho delirante. Obteve resultados. Modificou a vida das pessoas e costumes foram alterados. Se não houve uma tutela total, isto não significa que inexistiu um aumento da vigilância sobre as pessoas. E houve um melhoramento geral das condições de higiene. Embora, os pobres das cidades brasileiras não possuem - até hoje - condições mínimas de higiene e saneamento.

26. Consultar Turack, Cynthia Fevereiro. Mulher-Mãe: representações femininas no periódico A Mãe de Família (1879-1888). Rio de Janeiro: UNIRIO; 2008. Essa autora demonstra as articulações dos médicos com a pequena e embrionária indústria médica/farmacêutica. O profissional publicava um artigo recomendando determinado produto. Contudo, no mesmo veículo impresso, anúncios do seu serviço eram ofertados para a possível clientela. Será que, nos poucos consultórios existentes, esse médico indicava o produto aos pacientes?

27. Penna, Belisário. A mulher, a escola e o lar. S.D. Departamento de Arquivo e Documentação/ Casa de Oswaldo Cruz. Rio de Janeiro. Fundo Pessoal Belisário Penna. Manuscrito. 13 folhas. $\mathrm{BP} / \mathrm{PI} / \mathrm{TP} / 90002040-37$. 
Para concretizar o Plano de Educação Higiênica, Penna lançaria mão de múltiplos recursos educativos, palestras, cartazes, folhetos e novas tecnologias como o rádio e o cinema. No entanto, preservava aspectos coercitivos e/ou persuasivos. Muitos esforços foram dedicados à assistência e educação de gestantes, crianças e mães, com a finalidade de combater as doenças e construir padrões de comportamento. Os agentes envolvidos na higienização da sociedade, tendo em vista sua reformulação, compreenderam a importância da educação feminina, em virtude do seu papel na família. Contudo, não foi esquecida a importante função que as enfermeiras desempenhariam, pois tinham contato direto com as famílias no seu cotidiano, podendo atuar na consolidação dos hábitos. Penna ressaltou a importância dessas profissionais para a higiene. Identificada a ausência de educação como uma das causas da pobreza, do analfabetismo e, principalmente, da propagação de inúmeras doenças, uma das propostas seria a difusão da educação higiênica. Os conhecimentos científicos repassados às famílias lhes permitiriam cuidar adequadamente dos filhos, de modo a lhes garantir uma boa saúde. A mulher (mãe, professora e profissional de saúde), um dos alvos da estratégia médico-pedagógica, receberia uma especial atenção no início da gestação.

«Para o bem da sociedade e da pátria haverá, depois do lar e da família, função de maiores responsabilidades e mais dignificantes do que a de educador? E a quem cabe essa função, senão à mãe de família no lar e à educadora na escola?» ${ }^{28}$.

À escola caberia formar os corpos, modelando-os, treinando-os para a obediência por meio de regras. Essa visão de escola e educação, que não só aperfeiçoava o espírito como também o corpo, tornava indispensável a presença de novos conhecimentos e práticas a compor o universo pedagógico. O controle sobre os indivíduos deveria ocorrer em todas as esferas da vida social. Poder-se-ia fazer da escola, portanto, o centro irradiador do homem novo. E regenerar a raça nacional pela educação da higiene passou a ser o fundamento do discurso educativo-eugênico dos anos 1920, que entendia ser necessário instruir o povo, pois somente a educação conduziria à um

28. Penna, Belisário. Fundamento da sociedade. O lar próprio. S. D. Departamento de Arquivo e Documentação/Casa de Oswaldo Cruz. Rio de Janeiro. Fundo Pessoal Belisário Penna. 3 folhas. $\mathrm{BP} / \mathrm{PI} / \mathrm{TP} / 90002040-17$. 
país civilizado. Instrumento poderoso para a formação de hábitos sadios seria o exemplo do professor. Caberia ao mestre das classes de alfabetização enorme responsabilidade na formação do caráter nacional. Afinal, eles recebiam em primeira mão cérebros infantis e modeláveis.

Criando uma rede de vigilância que abrangia o universo privado dos cidadãos, tornava-se indispensável controlar a população para formar um povo perfeito do ponto de vista eugênico. E, se essas questões pertenciam ao universo político e social, isto é, da alçada do poder público, deveriam ser responsabilidade dos dirigentes da sociedade. Para o pensamento eugênico, alguns dos problemas médicos, derivavam da ausência de cuidados com o matrimônio. Dessa maneira, o casamento era um ato que garantiria o bom funcionamento da sociedade, se os pais tivessem uma saúde eugênica. Era indispensável que a mulher ao ligar o seu destino ao de um homem, pelo casamento, tivesse nítida compreensão da responsabilidade que estava assumindo perante a sociedade de constituir uma família para o progresso da coletividade, para o aperfeiçoamento físico e moral da espécie, com a preocupação primordial de gerar filhos eugênicos.

Chamamos atenção sobre os equívocos cometidos pelos autores de textos publicados no final dos anos 1970, que estudaram a história da saúde pública e da medicina no Brasil sob uma orientação foucaultiana. Vamos retornar a esse ponto. Ele é muito importante. Transparece nestes trabalhos, uma falsa idéia de que o poder da medicina e dos médicos era total. Depois de três décadas da edição desses livros, fica claro o alto grau de generalização presente nestas pesquisas, além da heterogeneidade teórica e metodológica. Embora, estes pontos assinalados não invalidam a pioneira contribuição dessas obras. Por exemplo, os livros Danação da Normae Ordem Médica ${ }^{29}$ abriram um campo de investigação. Contudo, concordamos com a análise crítica que afirma que Foucault teria causado uma influência nefasta nos estudos sobre saúde e medicina ${ }^{30}$.

É inegável a ausência de pesquisa empírica, em boa parte, dos estudos sobre história da saúde, supostamente produzidos, a partir da matriz foucaultiana. Mas, isto não significa que toda análise realizada sobre o tema que tenha utilizado conceitos oriundos de Foucault seja necessariamente

29. Costa, Jurandir Freire. Ordem médica e norma familiar. Rio de Janeiro: Graal; 1979. Machado, Roberto et al. Danação da norma. Rio de Janeiro: Graal; 1978.

30. Coelho, Edmundo Campos. As profissões imperiais. Medicina, engenharia e advocacia no Rio de Janeiro. 1822-1930. Rio de Janeiro: Record; 1999. 
equivocada. Certamente, os sanitaristas ou eugenistas ansiaram por controlar vários aspectos da vida, como Renato Kehl sonhou no trecho transcrito a seguir, mas devemos perguntar como as pessoas reagiram a essas idéias. Elas não eram robôs sem consciência ${ }^{31}$.

«Um indivíduo para casar-se terá de sujeitar-se a uma minuciosa análise do seu registro e da sua própria pessoa; só depois da folha corrida, fornecida pela repartição genealógica e do atestado de sanidade, terá o honroso direito ao casamento prolífico. Sim, prolífico, porque os indivíduos considerados inaptos à procriação terão apenas direito aos prazeres do hymeneu, quando previamente submetidos a esterilização» ${ }^{32}$.

Portanto, não devemos nos impressionar com a idéia de uma história despojada de sua temporalidade, forjando um esquema evolutivo no qual a medicina, o sanitarismo, ou mesmo o eugenismo, estariam evoluindo de um estágio a outro. As narrativas dos intelectuais médicos muitas vezes nos fazem crer em autênticas revoluções. Não que os movimentos nos quais os atores atuaram tenham sido obras de ficção, invenções de memorialistas ou de pesquisadores. Trata-se de suspeitar que, muitas vezes, avaliamos como total o poder ideológico dos médicos. Os heróis dessas jornadas descreveram com romantismo os seus atos. Mas, não são totalmente verdadeiras as descrições dos acontecimentos que teriam acabado com os cortiços sujos, criando uma cidade maravilhosa e limpa, ou a repercussão da palestra do famoso médico na Academia Nacional de Medicina, provocando uma reviravolta nos estudos médicos.

Não estamos negando as diferenças existentes, nem entre as propostas, e muito menos ignorando os perfis dos agentes sociais. A presença das teorias racistas e/ou eugenistas, nessa época em que, a rigor, poucos escapavam do determinismo biológico, imprimiram características ao campo. No entanto, ocorre que nem todo intelectual, sanitarista ou eugenista, comungava das mesmas posições políticas ou critérios racistas. Poucos nomes sustentavam as medidas eugênicas radicais. Se ignorarmos essa minoria, para os demais era possível a superação das deficiências raciais. Mesmo entre os membros da Sociedade Eugênica de São Paulo, ou entre os militantes da Liga Brasi-

31. Sobre esse assunto consultar Sampaio, Gabriela dos Reis. Nas trincheiras da cura. As diferentes medicinas no Rio de Janeiro imperial. Campinas: UNICAMP; 2001.

32. Kehl, 1929, n. 4, p. 21. 
leira de Higiene Mental, havia dissensões. Por exemplo, Renato Kehl olhava com extremo pessimismo o Brasil. Para ele, o país era uma mistura de raças incompatíveis. Para Roquette-Pinto, no entanto, o Brasil não era degenerado biologicamente. O que não devemos fazer é concluir, apressadamente, que a partir das nuances abria-se grandes clarões no campo.

\section{Considerações finais}

Concluindo, o discurso da educação higiênica tornou-se um dos pontos básicos da questão nacional. Foi legitimando-se a intervenção no indivíduo, introduzindo-se conhecimentos e práticas, que iriam prevenir a doença. As grandes transformações urbanísticas foram justificadas como imprescindíveis à boa saúde dos habitantes das cidades. Da mesma maneira, as transformações políticas e sociais eram apresentadas como urgentes para o funcionamento do corpo da nação. A partir do início do século XX, os dispositivos da ordem higiênica ofertaram os argumentos para o projeto de modernização da sociedade, representado por um ideal de educação e saúde. O discurso médico-pedagógico procurava responder ao problema de controlar uma população hostil às normas sanitárias, cuja racionalidade representava uma necessidade vital. A oposição popular às iniciativas saneadoras do Rio de Janeiro foi interpretada como uma manifestação de desordeiros e ignorantes, sobre a qual era dever do Estado impor a ordem. Desenvolveu-se, assim, o argumento de que era necessário, para o funcionamento da sociedade, a disciplina dos hábitos irracionais, para evitar os conflitos que ocorriam por mau funcionamento dos órgãos da sociedade.

Os intelectuais eugenistas pretendiam melhorar a raça nacional. Alguns desses atores sociais eugenistas tendiam a concordar com os sanitaristas. Os membros do Movimento Sanitarista, ao contrário dos intelectuais fortemente influenciados pelo racismo científico do século XIX, viam os problemas sociais da doença e miséria do Brasil como possíveis de serem erradicados através de um programa de políticas de educação e saúde. Gobineau e os demais intelectuais do racismo científico consideravam que a situação do Brasil devia-se a miscigenação. A mistura de raças causava degeneração nos descendentes. Os sanitaristas não concordavam completamente com esse diagnóstico. Os eugenistas tendiam a aceitar a possibilidade de transformação do povo brasileiro. No entanto, muitos acrescentavam seus próprios remédios. Entre as propostas estava, por 
exemplo, a esterilização compulsória nos casos extremos de degeneração, os loucos e os criminosos 33 .

Penna tinha consciência de que as ações planejadas para a reforma das políticas de saúde representavam um ideal que só poderia alcançar sua realização quando fosse compreendida por parcelas consideráveis da sociedade. Em vários textos ele alerta que as normas eram boas. No entanto, se por um aspecto, os códigos sanitários não eram compreendidos e obedecidos pelos homens das classes populares, por outro, as medidas tornavam-se uma ameaça ao poder político das classes mais privilegiadas. Não foram raras as críticas dos intelectuais eugenistas e sanitaristas ao controle exercido pelas autoridades locais em seus domínios territoriais nos distantes sertões. Certamente, os chefes políticos rurais não viam com bons olhos a vigilância pretendida pelo governo central sobre as condições higiênicas das fazendas. Esta tentativa de controle foi alimentada por intelectuais sanitaristas exercendo cargos públicos.

Diante da sociedade diagnosticada, os intelectuais sonharam com uma cidade organizada, cuja construção exigiria o planejamento dos espaços e das relações sociais. Nesta sociedade utópica, o discurso científico assumiria o status de organização total da formação social. Este discurso médico representou um importante papel na criação do imaginário de um Brasil moderno. Nesse ideal de uma sociedade brasileira organizada em função dos procedimentos científicos, o discurso cientificista procurou apreender todos os aspectos da realidade social. Assim, a figura do homem pobre, doente e analfabeto representaria o símbolo privilegiado das estratégias disciplinares. A afirmação destes modelos justificaria o investimento de poder na realização do sonho de uma sociedade formada por indivíduos racionais e saudáveis.

Sem dúvida, no Brasil, o discurso médico elaborou desde o século XIX uma estratégia de controle social, entendendo que a desorganização e o mau funcionamento da sociedade eram as causas das doenças, miséria e analfabetismo. Cabia aos intelectuais, atuar sobre os órgãos doentes, fossem naturais ou institucionais, visando neutralizar todo o perigo possível. Os objetivos desenvolvidos pela educação higiênica nesse período foram

33. Sobre os intelectuais racistas, sanitaristas e eugenistas, consultar Dos Santos, Ricardo Augusto. La eugenesia y el nuevo paraíso. In: Vallejo, Gustavo; Miranda, Marisa, eds. Derivas de Darwin. Cultura y política en clave biológica. Buenos Aires: Siglo XXI Editora Iberoamericana; 2010, p. 49-69. 
conseqüências do esforço para a criação de técnicas visando normatizar a vida cotidiana. Ela pretendeu dominar um universo de medidas destinadas a assegurar a saúde, contribuindo para hábitos de uma vida sadia e organizada por um corpo de especialistas. Tentava-se, assim, o enquadramento das atitudes, almejando, em decorrência, educar, segundo o ponto de vista da higiene, todo o povo. 
The Hygiene Education Project of Belisário Penna. 1900-1930

Ricardo Augusto Dos Santos ..................................

1.-Introduction. 2.-Belisário Penna. 3.-A country of sick people. 4.-Final considerations.

ABSTRACT: This paper aims to present and analyze the hygiene education project of Belisario Penna (1868-1939). This physician took part in the public health movement that sought, through reforms in public health policy and education, to change the conditions that made Brazil a country of the poor, sick and illiterate. We describe the main ideas expressed by Penna in the period between 1900 and 1930. For this purpose, we use his archive as a privileged source of this physician, one of the leading intellectuals of the time. 